\title{
Oocyte production in Nellore cows supplemented with long-chain fatty acid soaps
}

\author{
Moacir Rogério de Souza ${ }^{1}$, Geraldo Tadeu dos Santos ${ }^{2}$, Luciano Soares de Lima1', Josmar \\ Mazucheli $^{3}$, Lúcia Maria Zeoula ${ }^{2}$, Luiz Paulo Rigolon ${ }^{2}$, Fábio Luiz Bim Cavalieri ${ }^{4}$
}

\footnotetext{
${ }^{1}$ Universidade Estadual de Maringá, Programa de Pós-graduação em Zootecnia, Maringá, PR, Brasil.

${ }^{2}$ Universidade Estadual de Maringá, Departamento de Zootecnia, Maringá, PR, Brasil.

${ }^{3}$ Universidade Estadual de Maringá, Departamento de Estatística, Maringá, PR, Brasil.

${ }^{4}$ Centro Universitário Cesumar, Centro de Biotecnologia, Laboratório de Fertilização in vitro, Maringá, PR, Brasil.
}

\begin{abstract}
This study was conducted to evaluate the effects of long-chain fatty acid soaps (LCFAS) of soybean oil on the production and quality of aspirated cumulus-oocyte complexes (COC) of lactating Nellore (Bos taurus indicus) cows. The effects of LCFAS on the plasma concentration of lipoproteins, total cholesterol, triacylglycerol, urea N, and insulin were also addressed. Thirty lactating Nellore cows were randomly assigned to one of two dietary groups. Cows were grazed on a Tifton 85 pasture throughout the experiment (100 days). Treatments consisted of a supplement with no fat included (CONT); and a supplement containing $47.2 \mathrm{~g} / \mathrm{kg}$ of LCFAS on a dry matter basis. After 14 days of treatment, animals were subjected to $4.93 \pm 1.55$ rounds of consecutive ovum pickup (OPU) at intervals of $21.71 \pm 11.76$ days. Blood samples were collected from all cows throughout the experiment at 25-day intervals (four samples per cow). Cows that were fed LCFAS supplements and cows that were fed CONT supplements had similar numbers of total aspirated oocytes (viable and not viable) by OPU and grades of viable oocytes. Plasma concentrations of high-density lipoprotein (HDL) were increased in cows supplemented with LCFAS. Plasma concentrations of LDL and total cholesterol were increased by LCFAS supplementation after 50 days on dietary treatment and insulin concentration was increased from 75 days on treatment. Long-chain fatty acid soaps from soybean oil added at $47.2 \mathrm{~g} / \mathrm{kg}$ have no effect on the number of aspirated COC or their quality in Nellore lactating cows even with changes in plasma concentration of HDL, LDL, total cholesterol, and insulin. Thus, this supplementation has no benefits when the main objective is to improve oocyte production and quality.
\end{abstract}

Key Words: beef cattle, insulin, fat supplementation, lipid profile, ovum pick up

\section{Introduction}

Zebu cattle are well adapted to the tropical conditions (Costa et al., 2015) of high temperature and humidity, parasites, and low quality of forage. Thus, in Brazil, Zebu breeds such as Nellore have been successfully used for beef production. However, their reproduction and fertility are usually low when compared with taurine breeds.

Reproduction biotechnologies such as artificial insemination, timed artificial insemination, multiple ovulations with embryo transfer, and follicular aspiration coupled with in vitro embryo production have been extensively used to improve reproduction efficiency in beef herds (Marinho et al., 2012; Simoes et al., 2012).

Received September 25, 2014 and accepted December 13, 2015. Corresponding author: gtsantos@uem.br

http://dx.doi.org/10.1590/S1806-92902016000300008

Copyright (c) 2016 Sociedade Brasileira de Zootecnia. This is an Open Access article distributed under the terms of the Creative Commons Attribution License (http://creativecommons.org/licenses/by/4.0/), which permits unrestricted use, distribution, and reproduction in any medium, provided the original work is properly cited.
Additionally, diet formulation and nutritional management strategies could be useful to improve reproduction efficiency. Indeed, studies performed with taurine breeds have shown that adding fat rich in polyunsaturated fatty acids (PUFA) to the diet improves the fertility of dairy cows (Petit and Twagiramungu, 2006; Petit et al., 2008). According to Abayasekara and Wathes (1999), PUFA have positive effects on the ovaries, follicular dynamics, the corpus luteum (CL), progesterone production, ovulation, fertilization, and the maintenance of pregnancy. Furthermore, studies have suggested that PUFA may increase the number of follicles in bovines during the postpartum period (Beam and Butler, 1997; Staples et al., 1998). However, there is little information about fat supplementation and the possible effects of fatty acids on oocyte quality, especially regarding Zebu breeds.

We hypothesized that supplementation of Nellore cows with a source of PUFA such as soybean oil bypassing the rumen increases quantity and improves morphologic qualities of aspirated cumulus-oocyte complexes. Therefore, the present study was conducted to evaluate the effects of supplementing long-chain fatty acids soap (LCFAS) of 
soybean oil on the quantity and on the morphological quality of aspirated cumulus-oocytes complexes (COC) of lactating Nellore (Bos taurus indicus) cows. Plasma concentrations of lipoproteins, total cholesterol, triacylglycerol, urea $\mathrm{N}$, and insulin were also investigated to determine any potential interference with quantity and morphologic qualities of aspirated COC.

\section{Material and Methods}

Animals were cared for in accordance with the National Council for Control of Animal Experimentation. A total of 30 lactating Nellore cows (Bos taurus indicus) were randomly assigned to one of two dietary groups containing 15 cows. The groups were balanced according to age $(76 \pm 27 \mathrm{mo})$, parturition $(4.5 \pm 2.0 \mathrm{mo})$, days postpartum ( $35 \pm 14$ day), body weight $(593 \pm 67 \mathrm{~kg})$, and body condition score (6 \pm 0.1$)$ (9-point scale; Richards et al., 1986). Before the start the experiment, reproductive evaluations were performed using an ultrasound device (Aloka SSD500 , Tokyo, Japan) fitted with a $5 \mathrm{MHz}$ linear rectal probe (Aloka UST5820-5, Tokyo, Japan) to identify possible abnormalities or reproductive pathologies. No postpartum follicular aspirations were performed in cows before initiation of the experiment.

Cows were grazed on a Tifton 85 (Cynodon spp) pasture throughout the experiment. The pasture was divided into eight 0.55 ha paddocks, which were grazed rotationally by groups. Each group of cows was moved to a new paddock every 7 to 8 days, allowing for 25 days of rest. Pasture samples were plucked by hand from each paddock on the first and last days of grazing to evaluate the composition. Tifton 85 contained, on a dry matter (DM) basis, $185.7 \mathrm{~g} / \mathrm{kg}$ crude protein, $741.1 \mathrm{~g} / \mathrm{kg}$ neutral detergent fiber, $344.8 \mathrm{~g} / \mathrm{kg}$ acid detergent fiber, and $19.7 \mathrm{~g} / \mathrm{kg}$ ether extract. Water and mineral supplements were always available for the cows.

The experimental treatments consisted of a supplement with no fat included (CONT); and a supplement containing $47.2 \mathrm{~g} / \mathrm{kg}$ long-chain fatty acid soaps (LCFAS; Lacto Plus ${ }^{\circledR}$, Itajaí, SC, Brazil) on a DM basis. Lacto Plus contained,

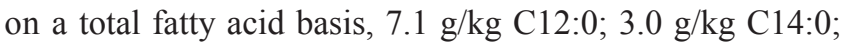
$137.9 \mathrm{~g} / \mathrm{kg} \mathrm{C} 16: 0 ; 1.0 \mathrm{~g} / \mathrm{kg} \mathrm{C} 16: 1$ cis-7; $1.0 \mathrm{~g} / \mathrm{kg} \mathrm{C} 17: 0 ; 52.7$ g/kg C18:0; 56.8 g/kg C18:1trans-9; 261.7 g/kg C18:1cis-9; 421.9 g/kg C18:2cis-6; 33.5 g/kg C18:3cis-9,cis-12,cis-15; $4.1 \mathrm{~g} / \mathrm{kg} \mathrm{C} 20: 0 ; 3.0 \mathrm{~g} / \mathrm{kg} \mathrm{C} 20: 1 ; 9.1 \mathrm{~g} / \mathrm{kg} \mathrm{C} 21: 0 ;$ and $7.1 \mathrm{~g} / \mathrm{kg}$ C22:0. Supplements (Table 1) were formulated to meet requirements for beef cows according to NRC (1996) and were offered once a day $(8.00 \mathrm{~h})$ over a period of 14 days of adaptation and 100 days of trial.
Blood samples were collected from all cows throughout the experiment at 25-day intervals (four samples per cow). Blood was drawn from the coccygeal vein into Vacutainer ${ }^{\circledR}$ tubes (Becton Dickinson and Cie, Rutherford, NJ, USA) containing heparin before the addition of supplements to determine concentrations of very low-density lipoprotein (VLDL), low-density lipoprotein (LDL), high-density lipoprotein (HDL), total cholesterol, triacylglycerol, urea, and insulin. Tubes were kept on ice until they were centrifuged at $1,600 \times g$ for $10 \mathrm{~min}$. Plasma was then separated and frozen at $-20{ }^{\circ} \mathrm{C}$ for subsequent analysis.

Dry matter was evaluated according to method no. 934.01 of AOAC (1998). Organic matter was determined via combustion in a muffle furnace according to method no. 942.05 of AOAC (1998). Total N was determined with a Tecnal TE-036/1 (Tecnal, Piracicaba, SP, Brazil) following method no. 988.05 of AOAC (1998). Ether extraction (EE) from diets was conducted with Tecnal TE-044/1 according to procedure no. 920.39 of AOAC (1998). The concentration of neutral detergent fiber (aNDF), including residual ash, was evaluated as described by Mertens (2002), by using heatstable $\alpha$-amylase and sodium sulfite. The acid detergent fiber content including residual ash was determined according to method 973.18 of AOAC (1998). The aNDF procedure was adapted to accommodate the use of the Ankom ${ }^{200}$ Fiber Analyzer (Ankom Technology Corp., Fairport, NY, USA). Protein, lactose, fat, and urea $\mathrm{N}$ concentrations in milk were

Table 1 - Ingredients and chemical composition of experimental supplements

\begin{tabular}{lcc}
\hline & \multicolumn{2}{c}{ Treatment } \\
\cline { 2 - 3 } Item & CONT & LCFAS \\
\hline Ingredient (g/kg DM) & \\
Corn silage & 501.2 & 528.4 \\
Ground corn & 319.3 & 216.9 \\
Soybean meal & 128.7 & 165.1 \\
Molasses & 12.5 & 11.8 \\
Limestone & 10.0 & 0.0 \\
Urea & 7.0 & 7.1 \\
Dicalcium phosphate & 3.0 & 4.2 \\
Antioxidant $(\mathrm{BHT})$ & 0.5 & 0.5 \\
Mineral mixture & & 18.9 \\
Lacto Plus & & \\
( & 18.0 & 47.2 \\
Nutrient composition & - & \\
Dry matter $(\mathrm{g} / \mathrm{kg})$ & & 405.4 \\
Organic matter $(\mathrm{g} / \mathrm{kg} \mathrm{DM})$ & 417.2 & 944.5 \\
Crude protein $(\mathrm{g} / \mathrm{kg} \mathrm{DM})$ & 949.5 & 155.9 \\
Ether extract $(\mathrm{g} / \mathrm{kg} \mathrm{DM})$ & 149.5 & 35.4 \\
Neutral detergent fiber $(\mathrm{g} / \mathrm{kg} \mathrm{DM})$ & 25.2 & 279.4 \\
Acid detergent fiber $(\mathrm{g} / \mathrm{kg} \mathrm{DM})$ & 192.4 & 198.6 \\
\hline
\end{tabular}

CONT - supplement with no fat included; LCFAS - long-chain fatty acid soaps; DM - dry matter; BHT - butylated hydroxytoluene.

${ }^{1}$ Contained (per kg, as-is basis): Ca - $123.0 \mathrm{~g}$; P - $90.0 \mathrm{~g}$; S - $18.0 \mathrm{~g}$; Na - $141.0 \mathrm{~g}$; $\mathrm{Co}-60.0 \mathrm{mg} ; \mathrm{Cu}-1,500 \mathrm{mg} ; \mathrm{Cr}-20.0 \mathrm{mg} ; \mathrm{Fe}-1,800 \mathrm{mg}$; I $75.0 \mathrm{mg} ; \mathrm{Mn}-1,800 \mathrm{mg}$; $\mathrm{Se}-17.0 \mathrm{mg}$; Zn - 4,500 mg; and F - $900.0 \mathrm{mg}$. 
analyzed by infrared spectrophotometry (Bentley model 2000; Bentley Instrument Inc., Chaska, MN, USA).

The plasma triacylglycerol (TG) concentration was determined via an enzymatic colorimetric method using glycerol-3-phosphate oxidase at $500 \mathrm{~nm}$ (kit 15710; Diasys Diagnostic Systems, Holzheim, Bavaria, Germany). The HDL and LDL concentrations were analyzed by colorimetric assays at $600 \mathrm{~nm}$ (kits 13521 and 14121, respectively; Diasys Diagnostic Systems, Holzheim, Bavaria, Germany). The VLDL concentration was estimated by dividing TG concentration by five, as described by Friedewald et al. (1972). Concentrations of total cholesterol were analyzed at $500 \mathrm{~nm}$ using an enzymatic photometric assay (kit 11300; Diasys Diagnostic Systems, Holzheim, Bavaria, Germany). Urea concentrations were determined at $340 \mathrm{~nm}$ (kit 1301; Diasys Diagnostic Systems, Holzheim, Bavaria, Germany), and plasma urea nitrogen (PUN) was obtained by multiplying the urea concentration by 0.47 (Hallett and Cook, 1971). Insulin hormone in plasma was determined by using a commercial kit (Abbott Diagnostics, Abbott Park, Illinois, USA).

After 14 days of adaptation to the experimental treatments, all animals were subjected to $4.93 \pm 1.55$ rounds of consecutive ovum pickup (OPU), at intervals of $21.71 \pm 11.76$ days. Before OPU procedures, the rectum was emptied, and the perineum and vulva were washed with running water before being wiped with a paper towel. Cows were given a local anesthetic agent of 3-5 mL of 2\% lidocaine without vasoconstrictors (Lidovet, Bravet, Engenho Novo, Rio de Janeiro, Brazil), which was injected epidurally between the last sacral and first caudal vertebrae. Ovum pickup was performed using an ultrasound (Aloka SSD-500, Tokyo, Japan) fitted with a transvaginal guide (WTA, Cravinhos, SP, Brazil) for follicular puncture, with a convex transducer of $5 \mathrm{MHz}$ (Aloka UST994T-5, Tokyo, Japan). Aspiration was performed using a $18 \mathrm{G}$ short disposable needle connected to a puncture system (WTA, Cravinhos, SP, Brazil) with a $50 \mathrm{~mL}$ polypropylene tube (TPP, Trasadingen, Schaffhausen, Switzerland) under continuous negative pressure $(80 \mathrm{mmHg}$, low rate equivalent of $13 \mathrm{~mL} / \mathrm{min}$ ) by using a vacuum pump (WTA, Cravinhos, SP, Brazil). The needle system was rinsed before and after each ovary aspiration with a sterile saline solution (phosphate buffered saline $(\mathrm{pH} 7.4)+1 \%$ fetal bovine serum $+5 \mathrm{IU} / \mathrm{mL}$ sodium heparin) and a new system was used for each cow. Follicular fluid was aspirated from follicles that ranged from 3 to $15 \mathrm{~mm}$.

In the laboratory, the aspirated follicular fluid from each cow was rinsed with a saline solution (phosphate buffered saline, $\mathrm{pH}$ 7.4) and then filtered using $75 \mu \mathrm{m}$ embryo filters (WTA, Cravinhos, São Paulo, Brazil). The retained content was transferred to a Petri dish retentate, after which the oocytes were counted and evaluated using a stereomicroscope (SMZ-645, Nikon, Tokyo, Japan).

Oocytes were classified as either viable or nonviable according to the number of layers of cumulus cells surrounding the oocytes and based on their cytoplasmic consistency (Lonergan, 1992). Viable oocytes were classified into three different grades: grade I (with more than three layers of cumulus), grade II (with two or three layers of cumulus cells), and grade III (with one layer of cumulus cells). Oocytes were considered not viable when found without layers of cumulus cells, with expanded cumulus cells, atretic, and degenerated.

Data on aspirated oocytes were assessed by fitting a Poisson regression model. The usual Poisson regression model was not proper likely due to presence of overdispersion. Then, Poisson distribution was fitted using random effect of cow according to the following model:

$\log \left(\mu_{i}\right)=\log$ (number of aspirations) $+\beta_{0}+\beta_{1} x_{1}+a_{i}$, in which $\log$ (number of aspirations) is the offset variable; $\exp \left(\beta_{0}\right)$ is the mean of oocytes when $\mathrm{x}=0(\mathrm{CONT}) ; \exp \left(\beta_{1}\right)$ is the treatment effect; and $a_{i \sim} N(0$, sigma $)$ is the random effect of cows.

The number of viable and non-viable oocytes was analyzed by adjusting a logistic regression model as follows:

$$
\operatorname{Logit}\left(p_{i}\right)=\alpha_{0}+\alpha_{i} x_{i}+a_{i},
$$

in which $\alpha_{0}$ is the chance of "success" for $\mathrm{x}=0$ (control treatment); $\alpha_{i}$ is the effect of treatment; and $a_{i \sim} N(0$, sigma $)$ is the random effect of animal.

Results for oocyte classification (grades I, II, and III) were assessed by fitting and adjusting a multinomial logistic regression model as described by (Hosmer et al., 2013).

Data regarding blood parameters (i.e., HDL, LDL, VLDL, total cholesterol, triacylglycerol, urea, and insulin) were analyzed as repeated measures using the MIXED procedure of SAS (Statistical Analysis System, version 9.0), according to the following general model:

$$
\mathrm{Y}_{\mathrm{ijk}}=\mu+\mathrm{T}_{\mathrm{i}}+\mathrm{S}_{\mathrm{j}}+\mathrm{A}_{\mathrm{k}}+\mathrm{TS}_{\mathrm{ij}}+\mathrm{e}_{\mathrm{ijk}} \text {, }
$$

in which $\mathrm{Y}_{\mathrm{ijk}}=$ the dependent variable; $\mu$ = overall mean; $\mathrm{T}_{\mathrm{i}}=$ fixed effect of treatment ( $\mathrm{i}=1$ to 2$) ; \mathrm{S}_{\mathrm{j}}=$ fixed effect of sampling over the days on dietary treatments $(j=1$ to 4$)$; $\mathrm{A}_{\mathrm{k}}=$ random effect of animal $(\mathrm{k}=1$ to 30$) ; \mathrm{TS}_{\mathrm{ij}}=$ effect of interaction between treatment and sampling over the days on dietary treatments; and $\mathrm{e}_{\mathrm{ijk}}=$ random residual error. Values of fit statistic for corrected Akaike's information criterion (AICc) were used to determine the most appropriate covariance structures. 


\section{Results}

Cows that were fed LCFAS supplements and cows that were fed CONT supplements had similar $(\mathrm{P}>0.05)$ numbers of total aspirated oocytes (viable and not viable) by OPU and grades of viable oocytes (Table 2 ).

There was an interaction $(\mathrm{P}=0.007)$ between treatment and sampling over days on dietary treatments for plasma

Table 2 - Means and standard deviations (in parentheses) of follicle aspirations performed in lactating Nellore cows supplemented with long-chain fatty acid soaps

\begin{tabular}{lcc}
\hline \multirow{2}{*}{ Item } & \multicolumn{2}{c}{ Treatment } \\
\cline { 2 - 3 } & CONT & LCFAS \\
\hline Number of cows & 15 & 15 \\
Number of ovum pick up & 70 & 78 \\
Aspirated oocytes/ovum pick up & $28.4(15.9)$ & $24.7(13.0)$ \\
Viable oocytes/ovum pick up & $25.2(14.8)$ & $21.2(11.1)$ \\
Grade I & $4.8(3.1)$ & $3.83(1.9)$ \\
Grade II & $5.7(2.4)$ & $5.0(1.8)$ \\
Grade III & $14.7(9.2)$ & $12.4(7.5)$ \\
Not viable oocytes/ovum pick up & $3.3(1.2)$ & $3.5(2.0)$ \\
\hline
\end{tabular}

CONT - supplement with no fat included; LCFAS - long-chain fatty acid soaps.

Means did not differ at $5 \%$ significance level $(\mathrm{P}>0.05)$. concentration of insulin (Table 3). Insulin concentration was similar between treatments when blood was sampled after 25 or 50 days. However, plasma concentration of insulin was increased in cows fed LCFAS from 75 days on dietary treatments.

There was no interaction $(\mathrm{P}=0.15)$ between treatment and sampling over days on dietary treatments for plasma urea N. Feeding LCFAS to cows did not affect plasma urea N.

No interaction between treatment and sampling over days on dietary treatments was observed $(\mathrm{P}=0.541)$ for plasma triacylglycerol. No effect of treatment was observed (0.463) as well.

For plasma concentration of HDL, no interaction between treatment and days on treatments was observed $(\mathrm{P}=0.159)$. Cows fed LCFAS showed a higher $(\mathrm{P}=0.042)$ concentration of plasma HDL.

There was an interaction between treatment and days on treatments $(\mathrm{P}<0.004)$ for plasma LDL concentration. Cows fed LCFAS showed lower concentrations of LDL when blood was sampled after 25 days, while after 50, 75, and 100 days, higher concentrations than those of cows fed CONT were observed.

Table 3 - Plasma composition in lactating Nellore cows supplemented with long-chain fatty acid soaps

\begin{tabular}{|c|c|c|c|c|c|c|c|}
\hline \multirow{2}{*}{ Item } & \multicolumn{4}{|c|}{ Days on dietary treatment } & \multicolumn{3}{|c|}{ P-value } \\
\hline & 25 & 50 & 75 & 100 & Treatment & Day & Interaction \\
\hline \multicolumn{8}{|l|}{ Insulin } \\
\hline CONT & 1.9 & 1.9 & 2.3 & 2.4 & \multirow{3}{*}{0.077} & \multirow{3}{*}{$<0.001$} & \multirow{3}{*}{0.007} \\
\hline LCFAS & 1.5 & 1.9 & 3.5 & 3.8 & & & \\
\hline SD & 0.2 & 0.2 & 0.6 & 0.4 & & & \\
\hline \multicolumn{8}{|l|}{ Urea N } \\
\hline CONT & 29.6 & 23.3 & 53.2 & 44.3 & \multirow{3}{*}{0.868} & \multirow{3}{*}{$<0.001$} & \multirow{3}{*}{0.15} \\
\hline LCFAS & 28.5 & 27.2 & 46.5 & 49.3 & & & \\
\hline SD & 2.0 & 0.9 & 1.7 & 1.4 & & & \\
\hline \multicolumn{8}{|c|}{ Triacylglycerol } \\
\hline CONT & 29.4 & 29.1 & 27.8 & 36.4 & \multirow{3}{*}{0.463} & \multirow{3}{*}{$<0.001$} & \multirow{3}{*}{0.54} \\
\hline LCFAS & 27.1 & 26.3 & 27.4 & 36.9 & & & \\
\hline SD & 1.57 & 1.6 & 0.97 & 1.7 & & & \\
\hline \multicolumn{8}{|l|}{ HDL } \\
\hline CONT & 77.4 & 83.3 & 92.7 & 85.3 & \multirow{3}{*}{0.042} & \multirow{3}{*}{$<0.001$} & \multirow{3}{*}{0.159} \\
\hline LCFAS & 77.7 & 90.5 & 97.1 & 93.8 & & & \\
\hline SD & 2.7 & 1.8 & 2.5 & 2.2 & & & \\
\hline \multicolumn{8}{|l|}{ LDL } \\
\hline CONT & 74.3 & 73.4 & 84.4 & 84.9 & \multirow{3}{*}{0.115} & \multirow{3}{*}{$<0.001$} & \multirow{3}{*}{0.004} \\
\hline LCFAS & 65.1 & 89.9 & 95.9 & 109.5 & & & \\
\hline SD & 4.0 & 5.7 & 5.6 & 8.3 & & & \\
\hline \multicolumn{8}{|l|}{ VLDL } \\
\hline CONT & 5.7 & 5.7 & 5.5 & 7.2 & \multirow{3}{*}{0.609} & \multirow{3}{*}{$<0.001$} & \multirow{3}{*}{0.656} \\
\hline LCFAS & 5.5 & 5.3 & 5.6 & 7.3 & & & \\
\hline SD & 0.3 & 0.3 & 0.2 & 0.4 & & & \\
\hline \multicolumn{8}{|c|}{ Total cholesterol } \\
\hline CONT & 157.4 & 162.5 & 182.7 & 177.5 & \multirow{3}{*}{0.077} & \multirow{3}{*}{$<0.001$} & \\
\hline LCFAS & 148.3 & 185.7 & 198.6 & 210.7 & & & 0.007 \\
\hline SD & 6.6 & 7.0 & 7.6 & 10.2 & & & \\
\hline
\end{tabular}

CONT - supplement with no fat included; LCFAS - long-chain fatty acid soaps; HDL - high-density lipoprotein; LDL - low-density lipoprotein; VLDL - very low-density lipoprotein. 
No interaction between treatment and sampling over days on dietary treatments was observed $(\mathrm{P}=0.656)$ for plasma VLDL. No effect of treatment was observed, either (0.609).

An interaction between treatment and sampling over days on dietary treatments was observed $(\mathrm{P}=0.007)$ for plasma total cholesterol. Feeding cows LCFAS did not affect total cholesterol concentration when blood was sampled after 25 days, while it increased concentrations of cholesterol when blood was sampled after 50,75, and 100 days.

\section{Discussion}

The present experiment was conducted to investigate the effects of supplementing LCFAS of soybean oil on oocyte production in lactating Nellore cows considering that most studies in this field of research have been performed in dairy cows.

Fat supplementation in our experiment did not alter the number of aspirated oocytes or their morphological classification. This is not consistent with a study (Adamiak et al., 2006) conducted with beef $\times$ dairy heifers, in which supplementation of calcium soaps of palm oil fatty acids increased the proportion of high-quality oocytes (grade I). However, the level of fat supplementation was $60 \mathrm{~g} / \mathrm{kg}$ DM, whereas in the present study we supplemented cows with $47.2 \mathrm{~g} / \mathrm{kg}$ DM. This suggests that a higher level of LCFAS supplementation than $47.2 \mathrm{~g} / \mathrm{kg} \mathrm{DM}$ is needed to improve the quality of oocytes in Nellore cows. It is also worth mentioning that in the present study cows had a moderate (6) body condition score (BCS), which could at least partially explain the lack of effect of fat supplementation on oocyte quality. In fact, Adamiak et al. (2006) reported that dietmediated alterations in oocyte quality were detectable only in low-BCS animals.

In the present study, we also investigated plasma concentration of lipoproteins, total cholesterol, triacylglycerol, urea $\mathrm{N}$, and insulin to determine any potential interference of LCFAS supplementation with production and quality of oocytes in Nellore cows. In fact, LCFAS supplementation increased HDL plasma concentration. Low-density lipoprotein and total cholesterol were also increased by LCFAS, but only after 50 days of treatment. These changes were likely a response to the higher intake of fat provided by treatment LCFAS, which probably required more plasma lipoproteins to support the larger amount of circulating PUFA. Indeed, lipoproteins such as HDL have been reported to carry a high concentration of PUFA (Offer et al., 2001). However, changes in plasma lipids were not sufficient to reach the reproductive system and did not affect oocyte production and quality as suggested by the lack of effect on aspirated $\mathrm{COC}$ and COC classification (Table 2). Perhaps, with a higher level of LCFAS supplementation, changes in plasma lipids could affect oocyte production.

Regarding insulin, LCFAS supplementation led to a higher plasma insulin concentrations after 75 days on dietary treatments. This may be related to a possible increased gluconeogenesis promoted by the higher intake of PUFA, which have been proposed to regulate hepatic gluconeogenesis. Indeed, unsaturated fatty acids have been previously reported to affect key transcription factors involved in the upregulation of gene coding for key gluconeogenic enzymes in rodents (Jump et al., 2005). However, in cows, this gluconeogenic effect seems to be time-dependent as suggested by our results, in which LCFAS supplementation increased insulin concentration only after 75 days of treatment. Increased plasma insulin has been previously proposed to affect follicular dynamics by increasing the number of ovarian follicles (Gong et al., 2002a,b). However, in the present study, the increased plasma insulin concentration after 75 days of treatment was not sufficient to increase the number of ovarian follicles as suggested by results of aspirated COC. A possible explanation is the absence of synchronization of follicular waves before OPU. Additionally, it is well established that dominant follicles have an inhibitory effect on the development of other follicles due to the secretion of estradiol and inhibin (Wolfsdorf et al., 1997). In the present study, aspirations were performed on random days, and so the presence of a dominant follicle may have influenced the recovery of COC.

\section{Conclusions}

Long-chain fatty acid soaps of soybean oil added at $47.2 \mathrm{~g} / \mathrm{kg}$ have no effect on the number of aspirated cumulus-oocyte complexes or their quality in Nellore lactating cows even with changes in plasma concentrations of HDL, LDL, total cholesterol, and insulin. Thus, this supplementation has no benefits when the main objective is to improve oocyte production and quality.

\section{Acknowledgments}

The authors express their gratitude to the staff of the in vitro fertilization laboratory Vitrogen (Uberaba, MG, Brazil) for their contribution to the present study. Special thanks to Luciano Borges for supporting the study by 
providing animals. M.R.S. was the recipient of a studentship from Fundação Araucária, PR-Brazil.

\section{References}

Abayasekara, D. R. and Wathes, D. C. 1999. Effects of altering dietary fatty acid composition on prostaglandin synthesis and fertility. Prostaglandins, leukotrienes, and essential fatty acids 61:275-287.

Adamiak, S. J.; Powell, K.; Rooke, J. A.; Webb, R. and Sinclair, K. D. 2006. Body composition, dietary carbohydrates and fatty acids determine post-fertilisation development of bovine oocytes in vitro. Reproduction 131:247-258.

AOAC - Association of Official Analytical Chemist. 1998. Official methods of analysis. 16th ed. AOAC, Gaithersburg, MP.

Beam, S. W. and Butler, W. R. 1997. Energy balance and ovarian follicle development prior to the first ovulation postpartum in dairy cows receiving three levels of dietary fat. Biology of Reproduction 56:133-142.

Costa, R. B.; Camargo, G. M. F.; Diaz, I. D. P. S.; Irano, N.; Dias, M. M.; Carvalheiro, R.; Boligon, A. A.; Baldi, F.; Oliveira, H. N.; Tonhati, H. and Albuquerque, L. G. 2015. Genome-wide association study of reproductive traits in Nellore heifers using Bayesian inference. Genetics Selection Evolution 47:1-9.

Friedewald, W. T.; Levy, R. I. and Fredrickson, D. S. 1972. Estimation of the concentration of low-density lipoprotein cholesterol in plasma, without use of the preparative ultracentrifuge. Clinical Chemistry 18:499-502.

Gong, J. G.; Armstrong, D. G.; Baxter, G.; Hogg, C. O.; Garnsworthy, P. C. and Webb, R. 2002a. The effect of increased dietary intake on superovulatory response to FSH in heifers. Theriogenology 57:1591-1602.

Gong, J. G.; Lee, W. J.; Garnsworthy, P. C. and Webb, R. 2002b. Effect of dietary-induced increases in circulating insulin concentrations during the early postpartum period on reproductive function in dairy cows. Reproduction 123:419-427.

Hallett, C. J. and Cook, J. G. 1971. Reduced nicotinamide adenine dinucleotide-coupled reaction for emergency blood urea estimation. Clinica Chimica Acta; International Journal of Clinical Chemistry 35:33-37.

Hosmer, D. W.; Lemeshow, S. and Sturdivant, R. X. 2013. Applied logistic regression. 3 rd ed. John Wiley, Hoboken, NJ.
Jump, D. B.; Botolin, D.; Wang, Y.; Xu, J.; Christian, B. and Demeure, O. 2005. Fatty acid regulation of hepatic gene transcription. The Journal of Nutrition 135:2503-2506.

Lonergan, P. 1992. Studies in the vitro maturation, fertilization and cultive of bovine follicular oocytes. Thesis (PhD). National Universty of Ireland, Dublin.

Marinho, L. S. R.; Untura, R. M.; Morotti, F.; Moino, L. L.; Rigo, A. G.; Sanches, B. V.; Pontes, J. H. F. and Seneda, M. M. 2012. Large-scale programs for recipients of in vitro-produced embryos. Animal Reproduction 9:323-328.

Mertens, D. R. 2002. Gravimetric determination of amylase-treated neutral detergent fiber in feeds with refluxing in beakers or crucibles: collaborative study. Journal of AOAC International $85: 1217-1240$

NRC - National Research Council. 1996. Nutrient requirements of beef cattle. 7th. rev. ed. National Academy Press, Washington, DC, USA.

Offer, N. W.; Marsden, M. and Phipps, R. H. 2001. Effect of oil supplementation of a diet containing a high concentration of starch on levels of trans fatty acids and conjugated linoleic acids in bovine milk. Animal Science 73:533-540.

Petit, H. V.; Cavalieri, F. B.; Santos, G. T.; Morgan, J. and Sharpe, P. 2008. Quality of embryos produced from dairy cows fed whole flaxseed and the success of embryo transfer. Journal of Dairy Science 91:1786-1790.

Petit, H. V. and Twagiramungu, H. 2006. Conception rate and reproductive function of dairy cows fed different fat sources. Theriogenology 66:1316-1324.

Richards, M. W.; Spitzer, J. C. and Warner, M. B. 1986. Effect of varying levels of postpartum nutrition and body condition at calving on subsequent reproductive performance in beef cattle. Journal of Animal Science 62:300-306.

Simoes, R. A. L.; Satrapa, R. A.; Rosa, F. S.; Piagentini, M.; Castilho, A. C. S.; Ereno, R. L.; Trinca, L. A.; Nogueira, M. F. G.; Buratini, J. and Barros, C. M. 2012. Ovulation rate and its relationship with follicle diameter and gene expression of the LH receptor (LHR) in Nelore cows. Theriogenology 77:139-147.

Staples, C. R.; Burke, J. M. and Thatcher, W. W. 1998. Influence of supplemental fats on reproductive tissues and performance of lactating cows. Journal of Dairy Science 81:856-871.

Wolfsdorf, K. E.; Diaz, T.; Schmitt, E. J.; Thatcher, M. J.; Drost, M. and Thatcher, W. W. 1997. The dominant follicle exerts an interovarian inhibition on FSH-induced follicular development. Theriogenology 48:435-447. 